\title{
A Comparative Study of Video-Assisted Thoracic Surgery with Thoracotomy for Middle Lobe Syndrome
}

\author{
Jian $\mathrm{Li}^{1,2} \cdot$ Chengwu Liu ${ }^{1,2} \cdot$ Yongsheng $\mathrm{Zhao}^{1,2} \cdot$ Chuan $\mathrm{Li}^{1,2} \cdot$ Lunxu Liu ${ }^{1,2}$
}

Published online: 2 November 2016

(C) The Author(s) 2016. This article is published with open access at Springerlink.com

\begin{abstract}
Objectives The aim of this study is to evaluate the feasibility and safety of video-assisted thoracic surgery (VATS) for the treatment of middle lobe syndrome (MLS) through comparison with thoracotomy during the same period. Methods We retrospectively reviewed all consecutive patients with MLS who underwent lobectomy or lingular segmentectomy between December 2005 and November 2015 in a single institute. Thirty patients were enrolled and divided into two groups: VATS group $(n=19)$ and thoracotomy group $(n=11)$. Data regarding the patients' demographics, medical history were collected and statistically compared.

Results All patients received successful middle lobe resection or lingular segmentectomy. In terms of operation time, blood transfusion, chest drainage amount, duration of chest drainage and postoperative complications, no significant differences were found between the two groups $(p>0.05)$. The mean intraoperative blood loss of VATS group was less than thoracotomy group $(79.0 \pm 63.9$ vs. $165 \pm 94.9 \mathrm{ml}, p=0.04)$. In VATS group, the mean length of postoperative hospital stay was $6.0 \pm 2.4$ days, shorter than that in group thoracotomy $(9.0 \pm 3.5$ days, $p=0.01)$. Conclusions VATS was a feasible and safe method for the surgical treatment of MLS in selected patients when no severe calcified lymph nodes surrounding hilus pulmonis was observed by preoperative chest CT scan.
\end{abstract}

\section{Introduction}

The name of "middle lobe syndrome" (MLS) was suggested by Graham et al. [1]. Extraluminal or intraluminal bronchial obstruction, recurrent atelectasis of the right middle lobe or left lingular segment was defined as MLS

Jian Li and Chengwu Liu have contributed equally to this study.

Lunxu Liu

lunxu_liu@aliyun.com

1 Department of Thoracic Surgery, West China Hospital, Sichuan University, No. 37, Guoxue Alley, Chengdu, Sichuan 610041, China

2 Western China Collaborative Innovation Center for Early Diagnosis and Multidisciplinary Therapy of Lung Cancer, Sichuan University, Chengdu 610041, China
[2]. Most patients with MLS would recover by applying antibiotics and bronchodilators, especially for non-obstructive type. Surgical intervention would be necessary for approximately one-third patients with MLS if conservative therapy fails, or complete bronchial obstruction [3-6]. Lobectomy or lingular segmentectomy was an effective surgical treatment of MLS. In 1948, Graham and Burford reported 12 patients with MLS underwent middle lobe lobectomy and detailed the intraoperative findings. After that, Fretheim and other authors sporadically reported surgical treatment for MLS (see Table 1). Among these studies, the majority of surgical procedures were performed via thoracotomy [7-10].

Over the past decade, with the continuous development of VATS technique, VATS has been applicable for most thoracic pathologies [11]. However, only few authors [12-14] reported VATS for the treatment of MLS. In this 
Table 1 Surgical treatment and postoperative outcomes of patients with MLS

\begin{tabular}{|c|c|c|c|}
\hline Authors & $\begin{array}{l}\text { Number of } \\
\text { patients and } \\
\text { (operation) }\end{array}$ & Surgical procedure & Outcome \\
\hline Graham et al. [1] & $12(12)$ & $\begin{array}{l}\text { Middle lobe lobectomy for all } \\
\text { patients }\end{array}$ & All were free of symptoms \\
\hline Fretheim [7] & $19(9)$ & $\begin{array}{l}\text { Middle lobe lobectomy for eight } \\
\text { patients }\end{array}$ & Expectoration persisted in one patient after operation \\
\hline $\begin{array}{l}\text { Albo and Grimes } \\
{[8]}\end{array}$ & $99(38)$ & $\begin{array}{l}\text { Middle lobe lobectomy or right } \\
\text { pneumonectomy for } 38 \\
\text { patients }\end{array}$ & Completely symptom-free after right middle lobectomy \\
\hline Saha et al. [4] & $98(31)$ & $\begin{array}{l}\text { Middle lobe lobectomy for } 29 \\
\text { patients } \\
\text { Wedge resection for two patients }\end{array}$ & $\begin{array}{l}\text { Recurrent symptoms presented in one patient } \\
\text { Pleural effusion developed in three people, wound infection in one } \\
\text { and atelectasis in one } \\
\text { One patient died of pulmonary embolus postoperatively }\end{array}$ \\
\hline Einarsson et al. [9] & $18(18)$ & $\begin{array}{l}\text { Middle lobe lobectomy for all } \\
\text { patients }\end{array}$ & $\begin{array}{l}\text { One patient was reoperated for bleeding and air leakage. Thirteen } \\
\text { patients were cured; five other patients were improved }\end{array}$ \\
\hline Seitz et al. [13] & $3(3)$ & $\begin{array}{l}\text { Thoracoscopic middle lobe } \\
\text { resection for three patients }\end{array}$ & One patient underwent secondary procedures \\
\hline $\begin{array}{l}\text { Gudbjartsson and } \\
\text { Gudmundsson } \\
{[17]}\end{array}$ & $20(20)$ & $\begin{array}{l}\text { Middle lobe resection for all } \\
\text { patients }\end{array}$ & $\begin{array}{l}\text { One patient died } \\
\text { One patient underwent secondary procedures because of massive } \\
\text { drainage amount }\end{array}$ \\
\hline Pejhan et al. [6] & $40(40)$ & $\begin{array}{l}\text { Middle lobe lobectomy for } 37 \\
\text { patients } \\
\text { Bronchotomy and tumor local } \\
\text { resection for one patient } \\
\text { Lower and middle bilobectomy } \\
\text { for one patient } \\
\text { Upper }+ \text { middle sleeve } \\
\text { lobectomy for one patient }\end{array}$ & All were cured \\
\hline
\end{tabular}

Patients except in Seitz' study underwent thoracotomy surgery

paper, we'd like to report one of the largest case series of MLS treated via VATS compared with traditional thoracotomy.

\section{Materials and methods}

This study included consecutive patients with MLS who were treated in the Department of Thoracic surgery of West China Hospital, Sichuan University between December 2005 and November 2015. According to surgical types, these patients were divided into VATS group (group V) and thoracotomy group (group T). Clinical data of each patient were collected and reviewed. The study protocol was approved by the institutional review board of West China Hospital.

All patients received preoperative chest computed tomography (CT) scan and fiberoptic bronchoscopy. All patients were placed in the lateral decubitus position under general anesthesia with double-lumen endotracheal tube and underwent middle lobe resection or lingular segmentectomy. With respect to surgical treatment, we have no special technique than others. Classic three-portal technique was used during VATS procedures. The observation port $(1 \mathrm{~cm})$, utility port $(3 \mathrm{~cm})$ and assistant incision $(1.5 \mathrm{~cm})$ were placed in the 7 th intercostal space at the mid-axillary line, the 3rd intercostal space at the anterior axillary line and the 9th intercostal space between the posterior axillary line and subscapular line, respectively. Both of the VATS right middle lobectomy and left lingular segmentectomy were performed following the concept of single direction as we described before [15]. Thoracotomy was performed through a classic posterolateral incision $(20-30 \mathrm{~cm})$ made in the 4th intercostal space. Tissues were sent to frozen section examination routinely. One chest tube would be placed at the end of each operation. All procedures were performed by thoracic surgeons who have the similar experience. Chest tube was removed when the daily drainage was $<200 \mathrm{~mL}$ and when no air leak was identified. Patients were discharged from the hospital when there was no main complication.

Data of each patient were collected from the medical records. Including gender, age, surgical approach, duration of operation, intraoperative blood loss, blood transfusion, 
Table 2 Demographic and baseline characteristics of all patients

\begin{tabular}{|c|c|c|c|}
\hline Variables & Group V $(n=19)$ & Group T $(n=11)$ & $p$ value \\
\hline Gender & & & 0.119 \\
\hline Male & 4 & 5 & \\
\hline Female & 15 & 6 & \\
\hline Age (years) & $42.5 \pm 11.3$ & $40.9 \pm 17.5$ & 0.764 \\
\hline \multicolumn{4}{|l|}{ Main symptoms } \\
\hline Cough + sputum production & 10 & 7 & \\
\hline Cough + Hemoptysis & 5 & 3 & \\
\hline Chest pain & 2 & 1 & \\
\hline Dyspnea & 1 & 0 & \\
\hline Others & 1 & 0 & \\
\hline Category & & & 0.433 \\
\hline Obstruction & 4 & 4 & \\
\hline Non-obstruction & 15 & 7 & \\
\hline Location of lesions & & & 0.617 \\
\hline Right middle lobe & 17 & 11 & \\
\hline Lingular & 2 & 0 & \\
\hline
\end{tabular}

Group V VATS group, group $T$ thoracotomy group

chest drainage amount, duration of chest drainage, postoperative complications and the length of postoperative hospital stay.

Statistical Product and Service Solutions (SPSS) software versions 17.0 (SPSS, Inc, Chicago, IL, USA) was used to analyze data. The Chi-square test was used to analyze categorical variables, and Mann-Whitney Wilcoxon test was used to analyze continuous variables. $p$ value $<0.05$ was considered statistically significant.

\section{Results}

A total of 30 patients with MLS were enrolled, including 21 females and 9 males. The baseline demographic characteristics of the two groups are shown in Table 2 . The mean age was 44.7 years (range 22-64 years). Among the 30 patients, $29(96.7 \%)$ presented signs and symptoms prior to operation: cough with sputum production (group V ten cases; group $\mathrm{T}$ seven cases), cough with hemoptysis (group V five cases; group $\mathrm{T}$ three cases), chest pain (group $\mathrm{V}$ two cases; group $\mathrm{T}$ one cases) and dyspnea (group V one cases; group T 0 case). The other one patient was completely asymptomatic. Non-obstructive type accounts for $73.3 \%$ (group V 15 cases; group $\mathrm{T} 7$ cases), the remaining $26.7 \%$ were obstructive type (group V four cases; group $\mathrm{T}$ four cases). The lesions were located in right middle lobes (group V 17 cases; group T 11 cases) or lingulars (group V two cases; group T 0 case). All patients received lobectomy or segmentectomy, 19 patients $(63.3 \%)$ underwent VATS and 11 patients $(36.7 \%)$ underwent thoracotomy.

Two cases in group $\mathrm{V}$ were converted to open procedure. The incidence was $10.5 \%$. The reasons were dense adhesions and enlarged calcified lymph nodes located in hilus pulmonis, respectively. During the operation for the second case, the middle lobe pulmonary artery was injured when dissecting the middle lobe bronchus, with blood loss of approximately $700 \mathrm{~mL}$. Anatomical lobectomy was performed for 24 patients (group V 15 cases; group T 9 cases). Anatomical lingular segmentectomy was performed for two patients (group V two cases; group $\mathrm{T} 0$ case). Nonanatomical lobectomy was performed for four patients (group V two cases; group $\mathrm{T}$ two cases).

No significant differences were found between the two groups in the duration of operation, blood transfusion, chest drainage amount, duration of chest drainage and postoperative complications $(p=0.326,0.716,0.076,0.346$, 0.454 , respectively, see Table 3 ). The mean intraoperative blood loss of group $\mathrm{V}$ was $79.0 \pm 63.9 \mathrm{~mL}$, less than that in group $\mathrm{T}(165.0 \pm 94.9 \mathrm{~mL}, p=0.04)$. The mean postoperative hospital stay length of group $\mathrm{V}$ was 6.0 days (range 3-15 days), shorter than in group $\mathrm{T}$ (9.0 days, range 4-17 days, $p=0.01$ ); the differences were statistically significant. Only one patient of group $\mathrm{T}$ received blood transfusion. The most common pathology of MLS in the study was inflammation $(n=21)$, followed by bronchiectasis $(n=3)$, granulomatous $(n=1)$ and tuberculosis $(n=1)$. One patient received anti-tuberculosis treatment 
Table 3 Perioperative clinical data of all patients

\begin{tabular}{|c|c|c|c|}
\hline Variables & Group V $(n=19)$ & Group $\mathrm{T}(n=11)$ & $p$ value \\
\hline \multicolumn{4}{|l|}{ Surgical method } \\
\hline Anotomical lobectomy & 15 & 9 & \\
\hline Anotomical segmentectomy & 2 & 0 & \\
\hline Unanotomical lobectomy & 2 & 2 & \\
\hline Duration of operation (min) & $122.3 \pm 33.4$ & $150.0 \pm 67.3$ & 0.326 \\
\hline Intraoperative blood loss (ml) & $79.0 \pm 63.9$ & $165 \pm 94.9$ & 0.04 \\
\hline Blood transfusion & $0 / 19$ & $1 / 11$ & 0.716 \\
\hline Chest drainage amount (ml) & $307.5 \pm 231.0$ & $510.4 \pm 408.3$ & 0.076 \\
\hline Duration of chest drainage (days) & $2.9 \pm 1.3$ & $3.6 \pm 1.8$ & 0.346 \\
\hline \multicolumn{4}{|l|}{ Histology } \\
\hline Infection & 12 & 9 & \\
\hline Bronchiectasis & 2 & 1 & \\
\hline Granulomatous & 1 & 0 & \\
\hline Tuberculosis & 1 & 0 & \\
\hline Others & 3 & 1 & \\
\hline Complications & 0 & 2 & 0.454 \\
\hline Pulmonary atelectasis & 0 & 1 & \\
\hline Air leakage & 0 & 1 & \\
\hline Postoperative hospital stay (days) & $6.0 \pm 2.4$ & $9.0 \pm 3.5$ & 0.01 \\
\hline
\end{tabular}

after confirmed tuberculosis by pathology. There was no intraoperative and postoperative mortality. Long-term postoperative follow-up was not analyzed.

\section{Discussion}

MLS is an uncommon clinical entity. Originally, Graham and his colleagues [1] defined this syndrome as atelectasis of middle lobe caused by enlarged lymph nodes compressing the middle lobe bronchus. During the past 60 years, the definition of MLS has been changed. Bronchial obstruction, recurrent atelectasis no matter located in the right middle lobe or lingular segment was defined as MLS [2]. However, MLS was predominantly located in right middle lobe. Except that the middle lobe bronchus has a narrow diameter and an angular takeoff from intermediate bronchus, there are two other factors: Firstly, the right middle lobe is relatively isolated compared with left lingular segment. Therefore, more space adjacent to bronchus was left for development and enlargement of neoplasm or lymph nodes. Secondly, as other authors reported [16], right middle lobe lacks collateral ventilation, and it was the other factor that right middle lobe was vulnerably to suffer MLS.

Although almost all patients with MLS presented syndromes preoperatively, the diagnosis of MLS is still hard only with medical history. Chest CT scan and fiberoptic bronchoscopy were necessary for diagnosis of MLS [4, 17]. The image of chest CT can show the location of lesions, surrounding the bronchus. Via fiberoptic bronchoscopy, intraluminal bronchus can be observed and the pathological diagnosis of MLS would be made. These two methods were useful for classification of MLS and preoperative evaluation. In this study, all patients received chest CT scan and fiberoptic bronchoscopy examination; no one was misdiagnosed.

According to the situation that the involved bronchus was completely obstructed or not, MLS can be classified into obstructive and non-obstructive types. Endobronchial tumour or tuberculosis, foreign bodies often cause the obstructive type [18, 19], while benign inflammation is the main cause of non-obstructive type. In this study, we found that operation for obstruction type was more difficult than that for non-obstruction type. When the lesion was located near the orifice of the bronchus, sleeve lobectomy was necessitated to make sure of negative stump especially when there was a neoplasm. For cases with outside compression caused by extraluminal tumor or lymph nodes, there might be no space between the lesion and the bronchus and dissection would be rather difficult.

The risk of conversion to thoracotomy was $2-23 \%$ in VATS lobectomies, and when the involved bronchus was surrounded by calcified lymph nodes, it would rise to $37 \%$ 
$[20,21]$. In some cases, anatomical dissection of the vessels and bronchus could not be achieved because of dense adhesions between them. Sometimes clamping the pulmonary trunk would be helpful for the following safe dissection. However, for some cases, even if we used sharp dissection or converted to thoracotomy, dissection of the vessels and bronchus was still impossible. Then, we might transect the bronchus and pulmonary vessels together using endostapler. After the transection, a 3-0 prolene suture was used to reinforce the stump to prevent bronchopleural fistula and bleeding. In this study, there was no postoperative bleeding or bronchopleural fistula in the four patients who underwent non-anatomical lobectomy.

Several limitations of our analysis were realized as follows: (1) Our study is a retrospective review; it cannot reach random assignment to treatment. (2) Although all procedures were performed by surgeons with similar experience, differences would present inevitably. And this study lacked unified criteria to select patients for VATS or thoracotomy. (3) This study only analyzed short-term patient data; hence, the long-term outcomes of VATS for MLS cannot be assessed. Considering the different surgical skills and experience of the surgeons, as well as the small patients cohort, the results did not indicate that all patients with MLS would benefit from VATS. However, considering the unusual entity of MLS, this study at least provided one of the largest cohort of patients undergoing VATS procedures. More experience of VATS in the surgical treatment of MLS is expected. We suggest that VATS resection could be performed for selected patients when no severe calcified lymph nodes surrounding hilus pulmonis are observed by preoperative chest CT scan.

\section{Conclusions}

In summary, our study indicated that VATS was a feasible and safe method for the surgical treatment of MLS in selected patients by experienced hands.

Acknowledgements We would like to thank Dr. Guowei Che, Zhu Wu, Yingli Kou and Yun Wang (West China Hospital, Sichuan University) for participating in the surgical procedures.

\section{Compliance with ethical standards}

\section{Conflict of interest None.}

Open Access This article is distributed under the terms of the Creative Commons Attribution 4.0 International License (http://crea tivecommons.org/licenses/by/4.0/), which permits unrestricted use, distribution, and reproduction in any medium, provided you give appropriate credit to the original author(s) and the source, provide a link to the Creative Commons license, and indicate if changes were made.

\section{References}

1. Graham EA, Burford TH, Mayer JH (1948) Middle lobe syndrome. Postgrad Med 4:29-34

2. Rosenbloom SA, Ravin CE, Putman CE et al (1983) Peripheral middle lobe syndrome. Radiology 149:17-21

3. Ayed AK (2004) Resection of the right middle lobe and lingular in children for middle lobe/lingual syndrome. Chest 125:38-42

4. Saha SP, Mayo P, Long GA et al (1982) Middle lobe syndrome: diagnosis and management. Ann Thorac Surg 33:28-31

5. Wagner RB, Johnston MR (1983) Middle lobe syndrome. Ann Thorac Surg 35:679-686

6. Pejhan S, Salehi F, Niusha S et al (2015) Ten years' experience in surgical treatment of right middle lobe syndrome. Ann Thorac Cardiovasc Surg 21:354-358

7. Fretheim B (1952) The so-called middle lobe syndrome. Thorax 7:156-158

8. Albo RJ, Grimes OF (1966) The middle lobe syndrome: a clinical study. Dis Chest 50:509-518

9. Einarsson JT, Einarsson JG, Isaksson H et al (2009) Middle lobe syndrome: a nationwide study on clinicopathological features and surgical treatment. Clin Respir J 3:77-81

10. Sehitogullari A, Sayir F, Cobanoglu U et al (2012) Surgical treatment of right middle lobe syndrome in children. Ann Thorac Med 7:8-11

11. Caronia FP, Fiorelli A, Ruffini E et al (2014) A comparative analysis of Pancoast tumour resection performed via video-assisted thoracic surgery versus standard open approaches. Interact CardioVasc Thorac Surg 19:426-435

12. Rothenberg SS (2003) Experience with thoracoscopic lobectomy in infants and children. J Pediatr Surg 38:102-104

13. Seitz G, Warmann SW, Szavay PO et al (2010) Thoracoscopic lobectomy as a treatment option for persistent middle lobe syndrome in children. Pediatr Int 52:e79-e81

14. Yu JA, Pomerantz M, Bishop A et al (2011) Lady Windermere revisited: treatment with thoracoscopic lobectomy/segmentectomy for right middle lobe and lingular bronchiectasis associated with non-tuberculous mycobacterial disease. Eur J Cardiothorac Surg 40:671-675

15. Liu L, Che G, Pu Q et al (2010) A new concept of endoscopic lung cancer resection: single-direction thoracoscopic lobectomy. Surg Oncol 19:e71-e77

16. Inners CR, Terry PB, Traystman RJ et al (1978) Collateral ventilation and the middle lobe syndrome. Am Rev Respir Dis 118:305-310

17. Gudbjartsson T, Gudmundsson G (2012) Middle lobe syndrome: a review of clinicopathological features, diagnosis and treatment. Respiration 84:80-86

18. Gudmundsson G, Gross TJ (1996) Middle lobe syndrome. Am Fam Physician 53:2547-2550

19. Chien HP, Lin TP, Chen HL et al (2000) Right middle lobe atelectasis associated with endobronchial silicotic lesions. Arch Path Lab Med 124:1619-1622

20. McKenna RJ Jr, Houck W, Fuller CB (2006) Video-assisted thoracic surgery lobectomy: experience with 1,100 cases. Ann Thorac Surg 81:421-425

21. Samson P, Guitron J, Reed MF et al (2013) Predictors of conversion to thoracotomy for video-assisted thoracoscopic lobectomy: a retrospective analysis and the influence of computed tomography-based calcification assessment. J Thorac Cardiovasc Surg 145:1512-1518 